\title{
Original Article (short paper) \\ Individual and average responses of sleep quality and daytime sleepiness after four weeks of strength training in adolescents
}

\author{
Maria Julia Lyra ${ }^{1}$, Antonio Henrique Germano-Soares ${ }^{2}$, Ladyodeyse da Cunha Silva Santiago ${ }^{1}$, Daniel da Rocha \\ Queiroz $^{2}$, Rafael Miranda Tassitano ${ }^{2,3}$, Ana Patrícia Siqueira Tavares Falcão ${ }^{4}$, Rodrigo Pinto Pedrosa ${ }^{2,5}$, Mônica Vilela \\ Heimer ${ }^{1}$, Marcos André Moura dos Santos ${ }^{1,2^{*}}$ \\ ${ }^{1}$ Universidade de Pernambuco, UPE, Camaragibe, PE, Brazil. ${ }^{2}$ Universidade de Pernambuco, UPE, Recife, PE, Brazil. \\ ${ }^{3}$ Universidade Federal Rural de Pernambuco, UFRPE, Recife, PE, Brazil. ${ }^{4}$ Instituto Federal de Pernambuco, Vitória de Santo \\ Antão, IFPE, PE, Brazil. ${ }^{5}$ Hospital Metropolitano Sul Dom Helder Câmara, IMIP Hospitalar, Cabo de Santo Agostinho, Brazil.
}

\begin{abstract}
Aims: To analyze the average and individual responses of sleep quality and daytime sleepiness in adolescents after four weeks of strength training. Methods: 19 adolescents with sleep problems recruited in the Federal Institute of Pernambuco, were subject to anthropometric evaluations as well as those for body composition assessment, a 1 repetition maximum test, the sleep parameters (Pittsburgh Sleep Quality Index-PSQI and Epworth Sleepiness Scale - ESS) and were submitted to four weeks of strength-training, performed alternately by segment, two sessions per week, according to recommendations for this population. Results: A decrease in the average PSQI score was observed (10.3 \pm 3.3 vs $8.8 \pm 4.0 ; \mathrm{p}=0.006)$, but not in ESS $(\mathrm{p}>0.05)$, after intervention. The individual analyses demonstrated that $\sim 63 \%$ of adolescents experienced reductions $\geq 3$ points in the PSQI and $\sim 58 \%$ of them experienced reductions $\geq 3$ points in the measure of daytime sleepiness. The prevalence of poor sleep quality and daytime sleepiness reduced from $84.2 \%$ to $68.4 \%$ and from $52.6 \%$ to $31.6 \%$, respectively. The comparisons of high and low responders to exercise training show that adolescents who reduced $\geq 3$ points in the score of a least one sleep parameter presented lower weight, fat mass, and fat percentage $(p<0.05)$. Conclusion: A short-term strength-training program is able to improve global sleep quality, but not daytime sleepiness in adolescents. Furthermore, the changes after training are highly heterogeneous. Further studies are required to better understand the effects of strength training on sleep parameters of adolescents.
\end{abstract}

Keywords: adolescence; sleep quality; strength training; daytime sleepiness; individual responses

\section{Introduction}

Sleep is an important component of daily circadian rhythm and plays a pivotal role in the promotion of health ${ }^{1}$. It is even more important during adolescence as this period is characterized by a series of biological and psychosocial changes that may affect adolescent sleep patterns (i.e. insufficient sleep duration and poor quality of sleep) ${ }^{2,3}$, resulting in a number of negative consequences (e.g. low academic achievement, impaired cognitive function, obesity) ${ }^{4,5}$. Therefore, improvements in sleep quality and duration should be targeted for improving adolescents' health.

It has been shown that physical activity is associated with longer sleep duration and better sleep quality in adolescents ${ }^{6}$. Moreover, a previous systematic review showed that aerobic exercise training improves overall sleep quality (ie. reduced latency to fall asleep, increased sleep time) ${ }^{7}$, suggesting that, despite the benefits of aerobic exercise, little attention has been given to other types of exercise (ie. strenght training). Interestingly, Loprinzi and Loenneke ${ }^{8}$ have shown that engagement in muscular strengthening activities is associated with a $19 \%$ greater chance to meet sleep duration guidelines
(7-8 hours/night) in adults; however, whether regular practice of strength exercise improves sleep parameters of adolescents remains unknown.

Interestingly, there is some evidence indicating that there is a substantial interindividual variability in response to exercise training ${ }^{9,10}$, suggesting that some individuals may experience significant responses, while others show minimal or even opposite responses to training. Therefore, examining the individual and average effect of strength training on sleep parameters of adolescents would be important for having a more complete evaluation of the efficacy of this mode of exercise in improving health in this population.

Thus, the aim of this present study was to analyze the average and individual responses of sleep quality and daytime sleepiness in adolescents after four weeks of strength training.

\section{Methods}

\section{Sample}

Nineteen adolescents of both genders ( 6 girls; 13 boys), 
recruited at the Federal Institute of Pernambuco (FIPE), participated in the present study. FIPE is located in an economically poor, rural zone of the state of Pernambuco, in northeastern Brazil. All students stay at FIPE from Monday to Friday. Males and females are housed separately, and have similar routines such as dining, class time, and bed time. In addition, alcohol and tobacco consumption is forbidden. The Research Ethics Committee of the University of Pernambuco approved the study procedure, which followed the established norms of the National Research Ethics Commission (CONEP: No. 89.701), and each adolescent who participated provided a written informed consent form.

The inclusion criteria were as follows: i) complaints of non-restorative sleep (poor sleep quality and sleep disturbance), ii) daytime sleepiness, iii) not involved in physical exercise programs, iv) no presence of any muscular or orthopedic injuries that might compromise the performance of the intervention sessions, v) did not perform moderate or vigorous physical activity during the 12 hours prior to the evaluation, vi) no use of sleeping drugs.

\section{Anthropometry and body composition}

Weight and height were measured by a digital scale (to the nearest $0.1 \mathrm{~kg}$; Filizola, São Paulo, Brazil) and a portable stadiometer (to the nearest $0.5 \mathrm{~cm}$; Sanny, São Paulo, Brazil), respectively. Measurements were taken with shoes off, feet together, and head in the Frankfurt horizontal plane ${ }^{11}$. Body mass index was calculated by my dividing weight $(\mathrm{kg})$ by the square of height $\left(\mathrm{m}^{2}\right)$.

To estimate the body composition, the two-compartment model (fat mass and lean mass) was adopted measuring skinfold thickness using a scientific adipometer (Lange ${ }^{\circledR}$, Cambridge Scientific Instruments, Cambridge, Maryland), with a constant pressure of $10 \mathrm{~g} / \mathrm{mm}^{2}$, and an accuracy of 1 $\mathrm{mm}$. The collection points were biceps, triceps, subscapular, and suprailiac and followed the recommendations previously described. The measurements were performed in triplicate and the median value was adopted. Relative body fat was estimated from the mathematical model proposed by Deurenberg, Weststrate, Seidell ${ }^{12}$.

\section{One repetition maximum ( $1 R M)$ test}

Prescription of the load in each exercise was based on the $1 \mathrm{RM}$ test. This test aims to evaluate the maximum force in the exercises used in the experimental program. In each exercise, the test was started with a warm-up (ten repetitions), using approximately $50 \%$ of the load established for the first $1 \mathrm{RM}$ attempt. After a two-minute interval, the adolescents were instructed to perform two replicates with the estimated 1RM load. If more than one repetition was performed correctly or if the participant failed to complete one repetition, the load was adjusted for a second attempt. For each exercise, participants had four attempts, with intervals of three to five minutes between attempts, to determine the 1RM load. To reduce possible faults in the identification of loads, strategies were adopted such as: explanation and technical demonstration of movements by the evaluators, before each exercise; correction and monitoring of the movement technique of each exercise, when necessary; and verbal encouragement during the test ${ }^{13}, 14$.

\section{Sleep parameters}

The Sleep Quality Index Questionnaire (Pittsburgh Sleep Quality Index-PSQI)

The PSQI was used to assess the quality of sleep, which determines an index of the severity and nature of the sleep disturbance ${ }^{15}$. The PSQI is a seven-domain (19 questions), selfrated questionnaire evaluating sleep habits during the last month. The seven-domain scores combine to provide an overall sleep quality index including: subjective sleep quality, sleep latency, sleep duration, habitual sleep efficiency, sleep disturbance, use of sleeping drugs, and daytime dysfunction. The possible scores range from zero to 21 and the higher the score, the worse the quality of sleep. For this study, a PSQI score $>5$ revealed that the individual had poor quality sleep and $>10$ indicated that the participant had a sleep disorder. This instrument had good reliability and high internal consistency $(\alpha=0.83)$ and good test-retest reliability $(r=0.85)^{15}{ }^{16}$. This instrument was duly validated in Portuguese for adolescents ${ }^{17}$.

\section{Epworth Sleepiness Scale (ESS)}

Daytime sleepiness was evaluated by using the Epworth Sleepiness Scale (ESS-BR), which has been widely used in adolescents ${ }^{18-20}$. This self-administered questionnaire aims to quantify the propensity to fall asleep during eight routine situations. The answers reach values between zero and 24 points, with 10 being the cut-off point. The interviewee should provide points from zero to three, quantifying their tendency (probability) to fall asleep ${ }^{21}$. The points given to each of the questions are added together. A total of 10 or more points is indicative of the presence of excessive daytime sleepiness ${ }^{21}$.

\section{Strength Training Session}

The training session was composed of eight exercises (leg extension, hamstring curls, calf raises, $45^{\circ}$ leg press, bench press, biceps curl, triceps pulley and lat pull-down) performed alternately by segment, at two sessions per week, for four weeks, following recommendations for this population ${ }^{22} .75 \%$ of 1 RM test was used as the load. For the Subjective Perception of Straining, OMNI-RES scale (OMNI - Resistance Exercise $S$ (ale) ${ }^{23}$ was used. Each volunteer was asked to point to the scale immediately after the end of the series. The recommendation was that the sense of straining stayed between eight and nine and if the number pointed to was below or above these numbers, the load would be reevaluated. 


\section{Statistical analysis}

All analyses were performed using SPSS software, version 21.0. The normality and homogeneity of the data were confirmed by the Shapiro-Wilk and Levene tests. Considering a power analysis of $80 \%$, an alpha error of $5 \%$, and an effect size of 0.4 , the sample size required was 19 adolescents. The two-way ANOVA was employed to compare the average changes on PSQI and ESS, between boys and girls. Comparisons of average changes on PSQI and ESS scores from pre- to post-intervention were performed by using the paired Student's t-test. Individual responses were obtained by calculating the absolute changes for each score ( $\Delta=$ post-intervention - pre-intervention), and the Independent Student's t-test was employed to compare general characteristics between adolescents who did or did not present reductions $\geq 3$ points in at least one sleep parameter, which represents $14 \%$ or higher of the total score. Statistical significance was set at $\mathrm{p}$ value $\leq 0.05$.

\section{Results}

The general characteristics of the adolescents are presented in Table 1.
Table 1. General characteristics of the adolescents included in this study $(\mathrm{n}=19)$

\begin{tabular}{ll}
\hline \multicolumn{1}{c}{ Variables } & \multicolumn{1}{c}{ Values } \\
\hline Age (years) & $16 \pm 2$ \\
Height $(\mathrm{m})$ & $1.67 \pm 0.70$ \\
Weight $(\mathrm{kg})$ & $62.9 \pm 11.9$ \\
Body mass index $\left(\mathrm{kg} / \mathrm{m}^{2}\right)$ & $22.4 \pm 3.2$ \\
Fat mass $(\mathrm{kg})$ & $20.7 \pm 9.8$ \\
Lean mass $(\mathrm{kg})$ & $42.2 \pm 5.8$ \\
Fat percentage $(\%)$ & $32.1 \pm 9.9$ \\
Averaged PSQI & $7.6 \pm 3.2$ \\
Averaged daytime sleepiness & $10.3 \pm 3.3$ \\
\hline
\end{tabular}

Data presented as mean and standard deviation

Since we showed no interaction between sex and time for both PSQI (mean $=-1.17$ [CI95\%: -3.69 to 1.35 ] for girls and -2.46 [CI95\%: -4.33 to -0.59 ] for boys; $\mathrm{p}=0.380$ ) and $\mathrm{ESS}$ (mean $=-1.17$ [CI95\%: -5.54 to 3.21] for girls and -1.69 [CI95\%: -4.34 to 0.96 ] for boys; $p=0.808$ ), the subsequent analyses were performed with boys and girls together.

The average changes in PSQI and ESS scores from pre- to post-intervention are presented in Figure 1. A decrease in the PSQI score ( $7.6 \pm 3.2$ vs $5.8 \pm 2.4 ; p=0.006$ ) was observed, while no changes for ESS score after strength training $(10.3 \pm 3.3 \mathrm{vs}$ $8.8 \pm 4.0 ; \mathrm{p}=0.131$ ) were observed.

Figure 1. PSQI (Panel A) and daytime sleepiness (Panel B) before and after four weeks of resistance training in adolescents.

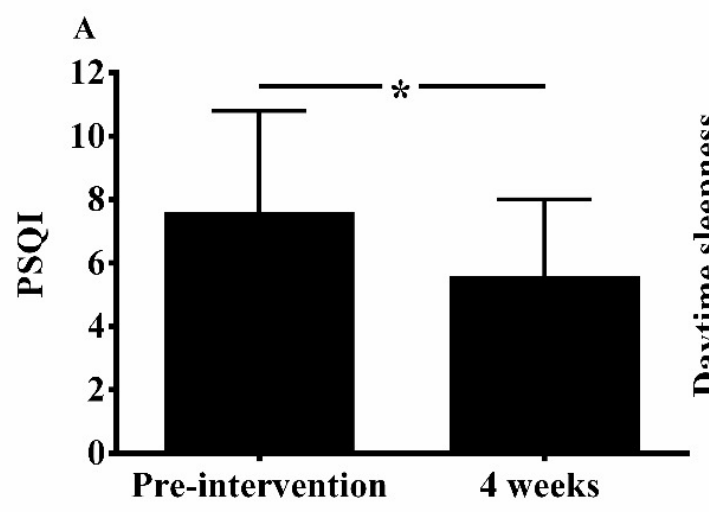

The individual analyses are presented in figure 2 . From the 19 adolescents submitted to exercise training, eight of them experienced reductions $\geq 3$ points in the PSQI score $(\sim 42 \%)$, while seven experienced reductions $\geq 3$ points in the daytime
B

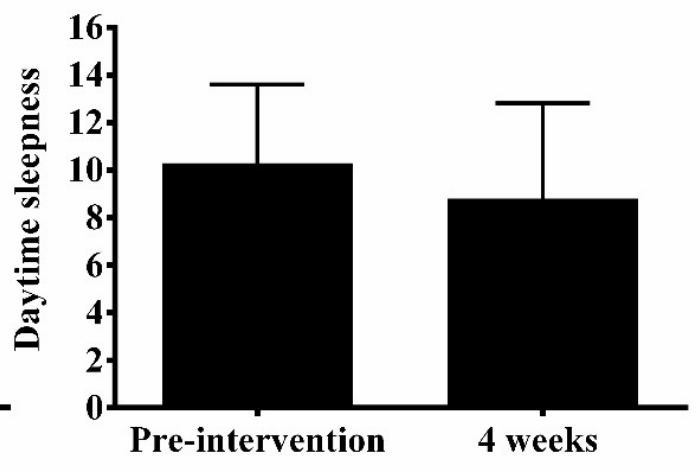

sleepiness score $(\sim 37 \%)$. Moreover, the prevalence of poor sleep quality and daytime sleepiness reduced from $84.2 \%$ to $68.4 \%$ and from $52.6 \%$ to $31.6 \%$, respectively, after the training. 
Figure 2. Pre-to post PSQI (Panel A) and daytime sleepiness (Panel B) individual changes after four weeks of resistance training.

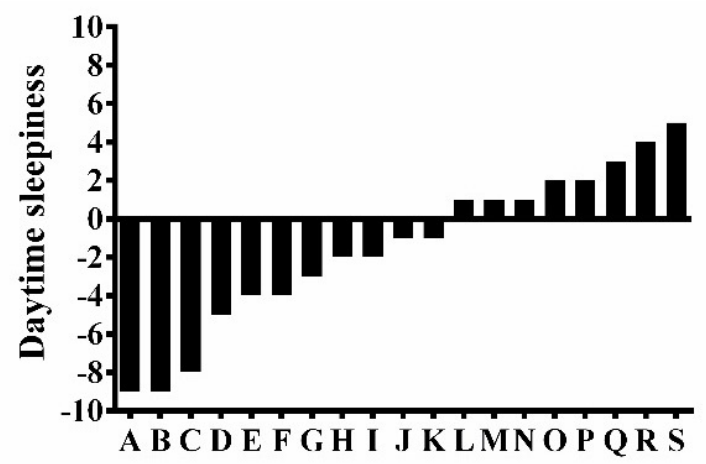

The comparisons of the general characteristics between high and low responders to exercise training are presented in Table 2 . The adolescents who reduced $\geq 3$ points in the score of

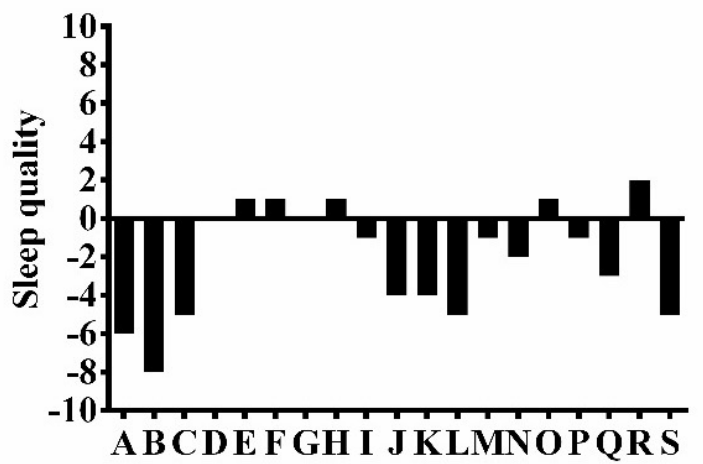

at least one sleep parameter presented lower weight, fat mass, and fat percentage $(\mathrm{p}<0.05)$; furthermore, there was a trend to have lower body mass index $(\mathrm{p}=0.068)$.

Table 2. Comparison of the general characteristics between adolescents who presented or did not present reductions $\geq 3$ points in the score of at least one sleep parameters

\begin{tabular}{lccc}
\hline & $\begin{array}{c}\text { Adolescents who did not present reductions } \\
(<\mathbf{3} \text { points) }\end{array}$ & $\begin{array}{c}\text { Adolescents who presented reductions } \\
(\geq \mathbf{3} \text { points })\end{array}$ & P value \\
\hline Age (years) & $16 \pm 2$ & $17 \pm 2$ & 0.384 \\
Height $(\mathrm{m})$ & $1.70 \pm 0.67$ & $1.65 \pm 0.68$ & 0.261 \\
Weight $(\mathrm{kg})$ & $70.4 \pm 13.9$ & $58.6 \pm 8.5$ & 0.045 \\
Body mass index $\left(\mathrm{kg} / \mathrm{m}^{2}\right)$ & $24.2 \pm 3.7$ & $21.4 \pm 2.5$ & 0.068 \\
Fat mass $(\mathrm{kg})$ & $37.8 \pm 8.3$ & $28.8 \pm 9.4$ & 0.036 \\
Lean mass $(\mathrm{kg})$ & $43.0 \pm 4.8$ & $41.8 \pm 6.5$ & 0.967 \\
Fat percentage $(\%)$ & $27.4 \pm 11.3$ & $16.8 \pm 6.5$ & 0.016 \\
\hline
\end{tabular}

Data presented as mean and standard deviation

\section{Discussion}

This is perhaps the first study examining the effects of a short-term strength-training program on sleep parameters of adolescents. The findings of this study indicated that four weeks of strength training induced improvements in both global sleep quality and daytime sleepiness in the majority the adolescents. Furthermore, such improvements are related to body mass index, body fat, and fat percentage in this subgroup.

It's well recognized that insufficient sleep is a relevant public health problem in adolescents. In fact, it has become increasingly common and frequent ${ }^{24}$, causing an increase in the prevalence of poor sleep quality and daytime sleepiness with advancing age ${ }^{25,26}$. This is further important since these problems are associated with an increased risk for cardiometabolic diseases (i.e. hypertension, diabetes, obesity). It also affects the process of growth and development ${ }^{27-29}$, and negatively impact the academic success of adolescents ${ }^{30}$.

In accordance with previous studies ${ }^{31,32}$, the current study showed that four weeks of strength training provoked an average reduction of the PSQI score, indicating an improvement in global sleep quality of the adolescents. In fact, Ferris, Williams, Shen, O'Keefe, Hale ${ }^{31}$ showed reductions on PSQI score after three months of strength training in older adults. Moreover, SilvaBatista et al. ${ }^{33}$ found that 12 weeks of strength training was able to reduce the PSQI score in healthy individuals, as well as in individuals with Parkinson's disease. Interestingly, the current study showed that even a short-term strength-training program (i.e. four weeks of training) was able to improve global sleep quality. Since we have previously demonstrated that a single session of strength exercise is able to improve sleep quality in adolescents, the results of the current study expand to the literature that this mode of exercise also has chronic effects ${ }^{13}$. Taken together, these results highlight the beneficial effects of strength training on sleep quality in different age groups.

Despite the improvements on average PSQI score, no changes were observed in the average daytime sleepiness after training. The likely explanation is that sleep quality is a wider indicator that may be influenced not only by the daytime sleepiness, but also by hours of sleep, depth of sleep, numbers of awakenings, 
and disposition for the day activities after awakening ${ }^{34}$. However, despite the lack of changes in the average score, the analysis of individual data showed a high heterogeneity in the changes in both PSQI and ESS. In total, $42.1 \%$ and $36.8 \%$ of the adolescents experienced reductions $\geq 3$ points in the PSQI and ESS, respectively. Moreover, $63.2 \%$ of the adolescents reduced $\geq 3$ points in at least one of these parameters, suggesting that the majority of the adolescents may benefit from the strength training.

Differences in sample characteristics may explain, at least in part, such interindividual variability in response to exercise training. In fact, adolescents who reduced $\geq 3$ points in at least one of the sleep parameters presented lower weight, fat mass and fat percentage in comparison with adolescents who did not present reductions. Thus, these aspects allow us to speculate that adolescents with a higher fat percentage are less likely to present sleep benefits after a short-term strength-training program. Corroborating this hypothesis, previous studies have shown that the frequency of daytime sleepiness is higher among obese individuals ${ }^{35}$. Furthermore, values of body mass index are associated with impaired daytime sleepiness in obese adolescents ${ }^{36}$. Although the cutoff point of $\geq 3$ points in the score was able to identify the characteristics of adolescents that responded and did not respond to training, further studies are warranted to examine whether changes of such magnitude are associated with adverse outcomes. Likewise, future studies are necessary to identify the mechanisms underlying the differences on sleep parameter changes between normal weight and obese adolescents following strength training programs. However, in this context, Loprinzi, Loenneke ${ }^{8}$ reported that sleep may help the body repair exercise-induced tissue damage occurring during wakefulness. Future mechanistic work is needed, mainly in adolescents, but the present findings suggest that, the engagement in muscular strengthening activities is associated with optimal sleep duration. This is an encouraging finding as, if corroborated by future prospective and experimental work, muscular strengthening activities may serve as a non-pharmacological, behavioralbased alternative to aerobic physical activity to help facilitate improved sleep among individuals.

From a practical point of view, the results of the current study showed the beneficial effects of a short-term strengthtraining program on global sleep quality and daytime sleepiness in adolescents. These improvements are important in view of the role of sleep on the changes that are experienced in this life period, which affect not only the risk for the onset of diseases, but also psychosocial health and school performance of the adolescents. Interestingly, we found that the adolescents with a higher percentage of body fat were less likely to benefit from resistance training, and therefore, the association of regular exercise practice with other strategies to improve body composition may be helpful in this subset.

The lack of a control group without exercise is definitively the main limitation of this study. Nevertheless, our results are comparable to other studies investigating sleep quality, daytime sleepiness and their consequences. Another potential limitation is the lack of objective tools to measure sleep, such as a sleepwake diary or actigraphy data, in association to references and concerns surrounding delayed sleep phase disorder. Despite having similar nutrition, the quantity or frequency of ingested caffeinated food was not evaluated, which may also have an influence on the results. Finally, the specific characteristics of the sample (i.e. institutionalized adolescents) may limit the generalizability of the results to other adolescents.

In conclusion, a short-term strength-training program is able to improve global sleep quality, but not daytime sleepiness in adolescents. Furthermore, the changes after training are highly heterogeneous. Further studies are required to better understand the effects of the strength training on sleep parameters of adolescents.

\section{References}

1. Van Dongen HP, Dinges DF. Investigating the interaction between the homeostatic and circadian processes of sleep-wake regulation for the prediction of waking neurobehavioural performance. J Sleep Res. 2003;12(3):181-7.

2. Dahl RE, Lewin DS. Pathways to adolescent health sleep regulation and behavior. J. Adolesc. Health. 2002;31(6):175-84.

3. Carskadon MA. Sleep in adolescents: the perfect storm. Pediatr. Clin. North Am. 2011;58(3):637-47.

4. Perez-Chada D, Perez-Lloret S, Videla AJ, Cardinali D, Bergna MA, Fernandez-Acquier M, et al. Sleep disordered breathing and daytime sleepiness are associated with poor academic performance in teenagers. A study using the Pediatric Daytime Sleepiness Scale (PDSS). Sleep. 2007;30(12):1698-703.

5. Cappuccio FP, Taggart FM, Kandala NB, Currie A, Peile E, Stranges $\mathrm{S}$, et al. Meta-analysis of short sleep duration and obesity in children and adults. Sleep. 2008;31(5):619-26.

6. Brand S, Gerber M, Beck J, Hatzinger M, Puhse U, HolsboerTrachsler E. High exercise levels are related to favorable sleep patterns and psychological functioning in adolescents: a comparison of athletes and controls. J. Adolesc. Health: official publication of the Society for Adolescent Medicine. 2010;46(2):133-41.

7. Yang PY, Ho KH, Chen HC, Chien MY. Exercise training improves sleep quality in middle-aged and older adults with sleep problems: a systematic review. J. Physiother. 2012;58(3):157-63.

8. Loprinzi PD, Loenneke JP. Engagement in muscular strengthening activities is associated with better sleep. Prev Med Rep. 2015;2:927-9.

9. Churchward-Venne TA, Tieland M, Verdijk LB, Leenders M, Dirks ML, de Groot LC, et al. There Are No Nonresponders to Resistance-Type Exercise Training in Older Men and Women. J Am Med Dir Assoc. 2015;16(5):400-11.

10. Bouchard C, An P, Rice T, Skinner JS, Wilmore JH, Gagnon J, et al. Familial aggregation of $\mathrm{VO}(2 \mathrm{max})$ response to exercise training: results from the HERITAGE Family Study. J Appl Physiol (Bethesda, Md : 1985). 1999;87(3):1003-8.

11. Lohman TG, Going SB. Body composition assessment for development of an international growth standard for preadolescent and adolescent children. Food Nutr Bull. 2006;27(4 Suppl Growth Standard):S314-25. 
12. Deurenberg P, Weststrate JA, Seidell JC. Body mass index as a measure of body fatness: age-and sex-specific prediction formulas. Br J Nutr. 1991;65(02):105-14.

13. Santiago LdCS, Lyra MJ, Cunha Filho M, Cruz PWdS, Santos MAMd, Falcão APST. Efeito de uma sessão de treinamento de força sobre a qualidade do sono de adolescentes. Rev Bras Med Esporte. 2015;21:148-52.

14. Brzycki M. Strength testing — predicting a one-rep max from repsto-fatigue. J. Phys. Health Educ. Recr. Dance. 1993;64(1):88-90.

15. Buysse DJ, Reynolds CF, Monk TH, Berman SR, Kupfer DJ. The Pittsburgh Sleep Quality Index: a new instrument for psychiatric practice and research. Psychiatry Res. 1989;28(2):193-213.

16. Chellappa SL, Araujo JF. Qualidade subjetiva do sono em pacientes com transtorno depressivo. Estud. psicol. 2007;12(3):269-74.

17. Passos MH, Silva HA, Pitangui AC, Oliveira VM, Lima AS, Araújo RC. Reliability and validity of the Brazilian version of the Pittsburgh Sleep Quality Index in adolescents. J Pediatr. 2016.

18. Pereira ÉF, Teixeira CS, Louzada FM. Sonolência diurna excessiva em adolescentes: prevalência e fatores associados. Rev Paul Pediatr. 2010;28:98-103.

19. Souza JC, Souza N, Arashiro ESH, Schaedler R. Sonolência diurna excessiva em pré-vestibulandos. J. bras. psiquiatr. 2007;56:184-7.

20. Gibson ES, Powles AC, Thabane L, O'Brien S, Molnar DS, Trajanovic N, et al. "Sleepiness" is serious in adolescence: two surveys of 3235 Canadian students. BMC Public Health. 2006;6:116.

21. Bertolazi AN, Fagondes SC, Hoff LS, Pedro VD, Barreto SSM, Johns MW. Validação da escala de sonolência de Epworth em português para uso no Brasil. J Bras Pneumol. 2009;35(9):877-83.

22. McCambridge T, Stricker P. Strength training by children and adolescents. Pediatrics. 2008;121(4):835-40.

23. Robertson RJ, Goss FL, Rutkowski J, Lenz B, Dixon C, Timmer J, et al. Concurrent validation of the OMNI perceived exertion scale for resistance exercise. Med Sci Sports Exerc. 2003;35(2):333-41.

24. Adolescent Sleep Working Group Coa, Council on school health School Start Times for Adolescents. Pediatrics. 2014;134(3):642-9.

25. Chen M-Y, Wang EK, Jeng Y-J. Adequate sleep among adolescents is positively associated with health status and health-related behaviors. BMC Public Health. 2006;6(1):59.

26. Borges GA, Schwarztbach C. Menarcheal age of youth from Marechal Cândido Rondon-PR. Rev Bras Cineantropom Desempenho Hum. 2003;5(2):15-21.

27. Gonzaga NC, SENA ASS, Coura AS, Dantas FG, Oliveira RC, MEDEIROS CCM. Sleep quality and metabolic syndrome in overweight or obese children and adolescents. Revista de Nutrição. 2016;29(3):377-89.

28. Natal CL, Lourenço TJ, Silva LA, Boscolo RA, Silva A, Tufik S, et al. Gender differences in the sleep habits of 11-13 year olds. Rev. Bras. Psiquiatr. 2009;31(4):358-61.
29. El Shakankiry HM. Sleep physiology and sleep disorders in childhood. Nat Sci Sleep. 2011;3:101.

30. Group ASW. School start times for adolescents. Pediatrics. 2014;134(3):642-9.

31. Ferris LT, Williams JS, Shen CL, O'Keefe KA, Hale KB. Resistance training improves sleep quality in older adults a pilot study. J Sports Sci Med. 2005;4(3):354-60.

32. Singh NA, Clements KM, Fiatarone MA. A randomized controlled trial of the effect of exercise on sleep. Sleep. 1997;20(2):95-101.

33. Silva-Batista C, Campos de Brito L, Corcos DM, Roschel H, Tulio de Mello M, Pimentel Piemonte ME, et al. Resistance Training Improves Sleep Quality In Subjects With Moderate Parkinson's Disease. J. Strength Cond. 2016.

34. Pereira ÉF, Daronco LSE, Teixeira CS, Kothe F, Merino EAD. Percepção de qualidade do sono e da qualidade de vida de músicos de orquestra. Rev psiquiatr clín (São Paulo). 2010;37(2):48-51.

35. Sena ASS, Cardoso AdS, Carvalho DFd, Medeiros JL, Coutinho GF, Albuquerque FCdL, et al. Excessive daytime sleepnessand cardiometabolic risk factors in children and teenagers with overweight. J Hum Growth Dev. 2013;23:24-30.

36. Feldner CBRdF, Zulmária Rezende; Rodrigues, Bruno Soares; Dias Nunes, João Elias; Santos, Heitor Cunha. Associação da ingestão demacronutrientes com o padrão de sono de adolescentes obesos. ConScientiae Saúde. 2015;14:592-9.

\section{Acknowledgments}

This study was supported by National Council for Scientific and Technological Development $(\mathrm{CNPq})$ and Coordination for the Improvement of Higher Education Personnel (CAPES).

\section{Corresponding author}

*Marcos André Moura dos Santos

Mailing address: Arnóbio Marques Street, 310. Escola Superior de Educação Física, Santo Amaro, Recife, PE.

Email: mmoura23@gmail.com

Manuscript received on June 29, 2017

Manuscript accepted on October 1, 2017

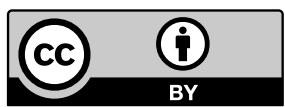

Motriz. The Journal of Physical Education. UNESP. Rio Claro, SP, Brazil - eISSN: 1980-6574 - under a license Creative Commons - Version 3.0 